\title{
Long-Haul Dense Space Division Multiplexed Transmission over Low-Crosstalk Heterogeneous 32-Core Transmission Line Using Partial Recirculating Loop System
}

Mizuno, Takayuki; Shibahara, Kohki; Ye, Feihong; Sasaki, Yusuke; Amma, Yoshimichi; Takenaga,
Katsuhiro; Jung, Yong-min; Pulverer, Klaus ; Ono, Hirotaka; Abe, Yoshiteru Total number of authors:

18

Published in:

Journal of Lightwave Technology

Link to article, DOI:

10.1109/JLT.2016.2615070

Publication date:

2017

Document Version

Peer reviewed version

Link back to DTU Orbit

Citation $(A P A)$ :

Mizuno, T., Shibahara, K., Ye, F., Sasaki, Y., Amma, Y., Takenaga, K., Jung, Y., Pulverer, K., Ono, H., Abe, Y., Yamada, M., Saitoh, K., Matsuo, S., Aikawa, K., Bohn, M., Richardson, D. J., Miyamoto, Y., \& Morioka, T.

(2017). Long-Haul Dense Space Division Multiplexed Transmission over Low-Crosstalk Heterogeneous 32-Core Transmission Line Using Partial Recirculating Loop System. Journal of Lightwave Technology, 35(3), 488 - 498. https://doi.org/10.1109/JLT.2016.2615070

\section{General rights}

Copyright and moral rights for the publications made accessible in the public portal are retained by the authors and/or other copyright owners and it is a condition of accessing publications that users recognise and abide by the legal requirements associated with these rights.

- Users may download and print one copy of any publication from the public portal for the purpose of private study or research.

- You may not further distribute the material or use it for any profit-making activity or commercial gain

- You may freely distribute the URL identifying the publication in the public portal 


\section{Long-haul Dense Space Division Multiplexed Transmission over Low-crosstalk Heterogeneous 32-core Transmission Line Using Partial Recirculating Loop System}

Takayuki Mizuno, Member, IEEE, Kohki Shibahara, Member, IEEE, Member, OSA, Feihong Ye, Yusuke Sasaki, Yoshimichi Amma, Katsuhiro Takenaga, Yong-min Jung, Klaus Pulverer, Hirotaka Ono, Senior Member, IEEE, Senior Member, OSA, Yoshiteru Abe, Makoto Yamada, Senior Member, IEEE, Kunimasa Saitoh, Member, IEEE, Member, OSA, Shoichiro Matsuo, Member, IEEE, Member, OSA, Kazuhiko Aikawa, Marc Bohn, David J.Richardson, Fellow, IEEE, Fellow, OSA, Yutaka Miyamoto, Member, IEEE, and Toshio Morioka, Member, IEEE, Fellow, OSA

\section{(Post-Deadline)}

\begin{abstract}
In this paper, we present long-haul 32-core dense space division multiplexed (DSDM) unidirectional transmission over a single-mode multicore transmission line. We developed a low-crosstalk heterogeneous 32-core fiber with a square lattice arrangement, and a novel partial recirculating loop system. The span crosstalk of the 51.4-km 32-core transmission line was less than $-34.5 \mathrm{~dB}$. This allowed the transmission of polarization division multiplexed 16 quadrature amplitude modulation (PDM-16QAM) signals through all 32-cores over a long distance exceeding a thousand $\mathrm{km}$. We demonstrate 32-core DSDM 20 wavelength division multiplexed (WDM) PDM-16QAM transmission over $1644.8 \mathrm{~km}$ with a high aggregate spectral efficiency of $201.46 \mathrm{~b} / \mathrm{s} / \mathrm{Hz}$. Additionally, we examine the effect of crosstalk on the transmission performance of each core, and show
\end{abstract}

Manuscript received June, 2016.

T. Mizuno, K. Shibahara, and Y. Miyamoto are with the NTT Network Innovation Laboratories, NTT Corporation, 1-1 Hikari-no-oka, Yokosuka, Kanagawa, 239-0847, Japan (e-mail: mizuno.takayuki@lab.ntt.co.jp; shibahara.kouki@lab.ntt.co.jp; miyamoto.yutaka@lab.ntt.co.jp).

F. Ye and T. Morioka are with the DTU Fotonic, Technical University of Denmark, DK2800 Kgs. Lyngby, Denmark (e-mail: feye@fotonik.dtu.dk, tomo@fotonik.dtu.dk).

Y. Sasaki, Y. Amma, K. Takenaga, S. Matsuo, and K. Aikawa are with the Fujikura Ltd., 1440, Mutsuzaki, Sakura, Chiba, 285-8550, Japan (e-mail yusuke.sasaki@jp.fujikura.com,_ yoshimichi.amma@jp.fujikura.com, katsuhiro.takenaga@jp.fujikura.com, shoichiro.matsuo@jp.fujikura.com, kazuhiko.aikawa@jp.fujikura.com).

Y. Jung, and D. J. Richardson are with the Optoelectronics Research Centre, University of Southampton, Southampton, SO17 1BJ, UK (e-mail: ymj@orc.soton.ac.uk,djr@orc.soton.ac.uk).

K. Pulverer, and M. Bohn are with the Coriant R\&D GmbH, St. Martin Str. 76, 81541 Munich, Germany (e-mail: klaus.pulverer@coriant.com, marc.bohn@coriant.com).

H. Ono and Y. Abe are with the NTT Device Technology Laboratories, NTT Corporation, 3-1 Morinosato-Wakamiya, Atsugi, Kanagawa, 243-0198, Japan (e-mail: ono.hirotaka@lab.ntt.co.jp, abe.yoshiteru@lab.ntt.co.jp).

M. Yamada is with the Osaka Prefecture University, 1-1 Gakuen-cho, Sakai, Osaka 599-8531, Japan (e-mail: myamada@eis.osakafu-u.ac.jp).

K. Saitoh is with the Graduate School of Information Science and Technology, Hokkaido University, Sapporo 060-0814, Japan (e-mail: ksaitoh@ist.hokudai.ac.jp).

Color versions of one or more of the figures in this paper are available online at http://ieeexplore.ieee.org

Digital Object Identifier that the Q-penalty has strong correlation with inter-core crosstalk.

Index Terms - Coherent communications, crosstalk, long-haul transmission, multicore fiber (MCF), optical communication systems, optical fiber communication, optical fibers, space division multiplexing (SDM), spectral efficiency, wavelength division multiplexing (WDM).

\section{INTRODUCTION}

$\mathrm{S}$ PACE division multiplexing (SDM) has been studied intensively as the next generation multiplexing technology for increasing capacity of optical fiber transmission systems [1] Many transmission experiments have been performed using multicore fibers (MCFs) or few-mode fibers (FMFs), and have demonstrated high capacity [2-6] and long-distance [7-14] transmission. Figure 1 shows the spatial multiplicity as a function of distance in recent SDM experiments. MCFs with seven to 19 cores, and FMFs with three to six modes were commonly used as the transmission media. With a view to further increase capacity, we have presented dense SDM (DSDM) transmission with over 30 spatial multiplicity by simultaneous use of multiple core and multiple mode multiplexing. Polarization division multiplexed 32 quadrature amplitude modulation (PDM-32QAM) signals were transmitted over $40.4 \mathrm{~km}$ 12-core $\times 3$-mode multicore few-mode fiber (MC-FMF) with a high aggregate spectral efficiency (SE) of $247.9 \mathrm{~b} / \mathrm{s} / \mathrm{Hz}$ [15]. Subsequent experiments have further advanced multicore multimode transmission technology, including $200 \mathrm{~Tb} / \mathrm{s}$ high capacity transmission over 7 -core $\times 3$-mode fiber [16], transmission of 12-core $\times 3$-mode PDM-QPSK signals over $527-\mathrm{km}$ realized by the first multicore multimode recirculating loop experiment [17], fabrication of 36-core $\times 3$-mode fiber [18], demonstration of 19-core $\times$ 6 -mode fiber and $2.05 \mathrm{~Pb} / \mathrm{s}$ transmission capacity [19,20], and the realization of 19 -core $\times 6$-mode fiber with a relative core multiplicity factor of more than 60 [21]. Although these reports 


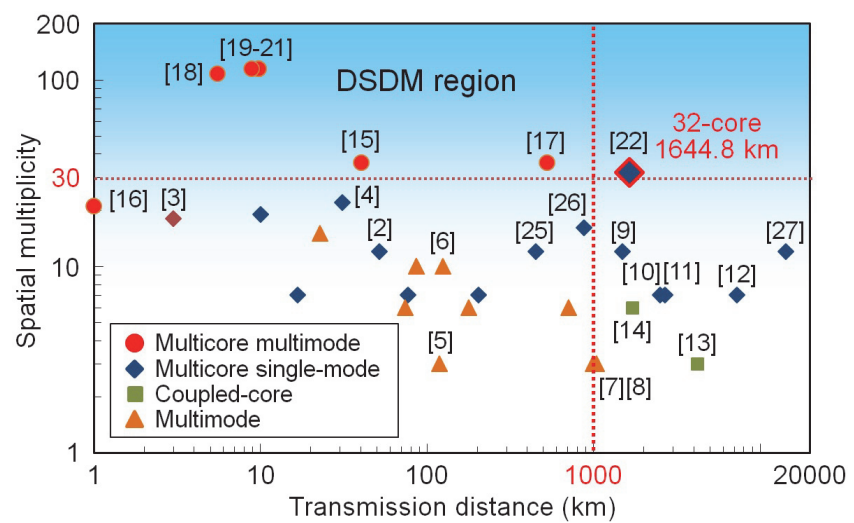

Fig. 1. Spatial multiplicity as a function of distance in recent SDM experiments

have shown the potential for further capacity scaling, the transmission distance was limited to around $500 \mathrm{~km}$ for the MC-FMFs with 36 spatial multiplicity [17], and less than 10-km for MC-FMFs with over 100 spatial multiplicity [18-21] As regards long-haul transmission exceeding $1000 \mathrm{~km}$, three-mode $[7,8], \quad 12$-core bi-directional (six-core unidirectional) [9], seven-core [10-12], three- and six-coupled-core $[13,14]$ transmission have been achieved. However, the spatial multiplicity of these experiments was less than seven. In future scalable and flexible optical transport network, long-haul DSDM system with more than 30 spatial channels and over $1000 \mathrm{~km}$ transmission distance is necessary for application to terrestrial networks. To reach this target with multicore transmission requires overcoming the tradeoff between increasing core-count, maintaining sufficient effective area $\left(A_{\text {eff }}\right)$, and reducing inter-core crosstalk within the limited cladding diameter considering fiber reliability.

In this paper, we describe the first demonstration of the long-haul DSDM transmission with over 30 spatial multiplicity and over $1000 \mathrm{~km}$ distance [22]. First, we review our low-crosstalk heterogeneous 32-core single-mode transmission line and our novel partial recirculating loop system, and then we present the experimental demonstration of the 32-core single-mode unidirectional transmission of PDM-16QAM signals over $1644.8 \mathrm{~km}$. In addition, we investigate the effect of inter-core crosstalk on transmission performance.

This paper is organized as follows. Section II presents the low-crosstalk DSDM transmission line consisting of a heterogeneous single-mode 32-core fiber and free-space optics type fan-in/fan-out (FI/FO) devices. Section III reviews the experimental setup of conventional long distance transmission experiments and proposes our novel partial recirculating loop system. Section IV describes the experimental setup and Section V discusses the experimental results of the long-haul DSDM transmission and the verification of the relation between inter-core crosstalk and transmission performance. Section VI summarizes the main content and concludes the paper.

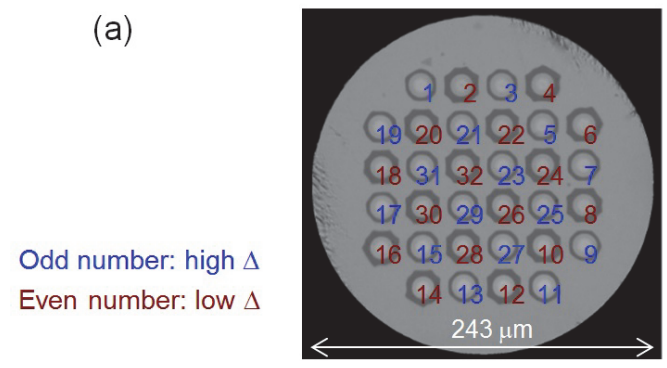

(b)

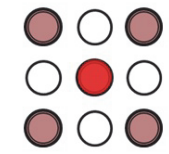

Second nearest cores (same refractive index type, diagonal position) (c)

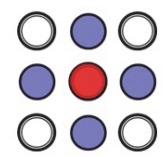

First nearest cores (different refractive index type, nearest position)
Fig. 2. (a) Cross sectional view of the heterogeneous 32-core single-mode $\mathrm{MCF}$, (b) four cores in the diagonal position with the same refractive index type relative to the center core, and (c) four cores in the nearest position with the different refractive index type relative to the center core.

\section{LOW-CROSSTALK 32-CORE TRANSMISSION LINE}

We have previously designed and fabricated a heterogeneous 30-core single-mode MCF using four types of refractive index design, and a homogeneous 31-core quasi-single-mode MCF [23]. The core arrangement of both of these fibers were based on a hexagonal closed-pack structure, where the 30 and 31 cores were densely arranged within a cladding diameter of 228 and $231 \mu \mathrm{m}$, respectively, typical for an MCF. The fiber length was 9.6 and $11.0 \mathrm{~km}$, and the $A_{\text {eff }}$ at $1550 \mathrm{~nm}$ was 77 and 75 $\mu \mathrm{m}^{2}$, respectively. The span crosstalk including fan-in/fan-out (FI/FO) devices of the 30-core and 31-core fiber was -31.9 and $-21.6 \mathrm{~dB}$, respectively. We define the inter-core crosstalk as the difference between the power of light output from the core under measurement when light was input only to the core under measurement and when light with equal intensities were input to all other cores. Although we showed that these DSDM fibers are capable of transmitting PDM- quadrature phase shift keying (QPSK) and PDM-16QAM signals, further reduction of inter-core crosstalk was required in order to realize long-haul DSDM transmission.

We have designed and fabricated a novel heterogeneous 32-core single-mode MCF to realize a low-crosstalk DSDM transmission line suitable for long-haul transmission. Figure 2 (a) shows the cross sectional view of the heterogeneous 32-core fiber [24]. A square lattice arrangement effectively minimizes inter-core crosstalk for heterogeneous MCF having two types of refractive index designs. The odd and even numbered cores representing cores with higher and lower refractive index difference, respectively, were placed adjacent to each other to suppress crosstalk. Trench structure was formed around each core for additional crosstalk reduction. The length of the fabricated MCF spool was $51.4 \mathrm{~km}$, the core pitch was $29.0 \mu \mathrm{m}$, and the cladding diameter was $243 \mu \mathrm{m}$. The cutoff wavelength 
(a)

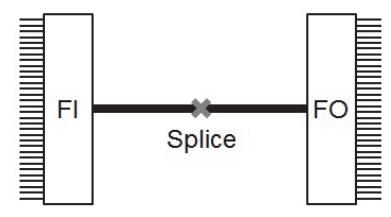

(b)

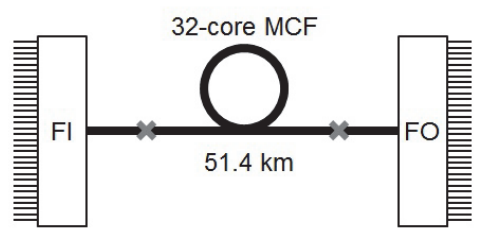

Fig. 3. Schematic diagram showing the components and splicing points for (a) measuring the characteristics of the free-space optics based 32-channel FI/FO devices, and (b) constructing the 32-core DSDM transmission line.

at a length of $1 \mathrm{~km}$ was $<1.53 \mu \mathrm{m}$. The attenuation and the $\mathrm{A}_{\text {eff }}$ at $1550 \mathrm{~nm}$ was $0.24 \mathrm{~dB} / \mathrm{km}$ and $>80.3 \mu \mathrm{m}^{2}$, respectively.

The inter-core crosstalk of the MCF depended on the position of the cores. The worst crosstalk was $<-39.4 \mathrm{~dB}$ when light was input to the second nearest cores (four adjacent cores with the same refractive index type in the diagonal position relative to the core under interest as shown in Fig. 2 (b)). On the other hand, the inter-core crosstalk was $<-54.0 \mathrm{~dB}$ when light was input to the first nearest cores (four adjacent cores with the different refractive index type in the nearest position relative to the core under interest as shown in Fig. 2 (c)), and it was negligible even though the inter-core distance was smaller than that of the cores in the diagonal position. This result reveals that the inter-core crosstalk from cores with the different refractive index type is effectively suppressed by the destructive interference of light due to difference in propagation constants.

We used free-space optics based [25] 32-channel FI/FO devices for multi/demultiplexing light into/from the 32-core fiber. First, the MCF-side of the FI and FO devices were directly spliced as shown in Fig. 3(a), and the characteristics were measured. The insertion loss ranged from 0.8 to $1.4 \mathrm{~dB}$, and the worst crosstalk ranged from -39.5 to $-46.7 \mathrm{~dB}$ at 1550 $\mathrm{nm}$. Then, the FI and FO devices were each spliced to the input and output of the $51.4-\mathrm{km}$ spool of the 32-core MCF, respectively, to construct a 32-core DSDM transmission line. The total span loss and the worst inter-core crosstalk including the $\mathrm{FI} / \mathrm{FO}$ devices were $<14.1 \mathrm{~dB} /$ span and $<-34.5 \mathrm{~dB} /$ span at $1550 \mathrm{~nm}$, respectively.

Figure 4 shows the crosstalk after 1000-km transmission as a function of the number of core per fiber in a single-mode MCF. The filled plots show characteristics of an MCF transmission line including a fiber and FI/FO devices, and the blank plots show characteristics of a plain MCF. The $1000-\mathrm{km}$ crosstalk was estimated from per span or per length crosstalk values given in references assuming that the crosstalk accumulates linearly with distance. The dotted lines also shown in the figure are the crosstalk levels required for various modulation formats assuming $0.5 \mathrm{~dB}$ penalty $[26,27]$. Crosstalk would normally increase when we increase the number of core in an MCF. Technique such as bi-directional transmission may reduce crosstalk. However, no MCF transmission lines have ever reached the target area of over 30 cores and a worst crosstalk of less than around -19 to $-31 \mathrm{~dB} / 1000 \mathrm{~km}$. By the heterogeneous design and the square lattice arrangement, we have successfully reduced the worst crosstalk to $<-21.6 \mathrm{~dB}$ even after $1000 \mathrm{~km}$ making long-haul DSDM transmission feasible for the first time.

\section{Partial Recirculating Loop System}

Features of long distance transmission experiments over an MCF transmission line are listed in Table 1. Various experimental setups have been employed for approximating long distance MCF transmission line. The commonly used

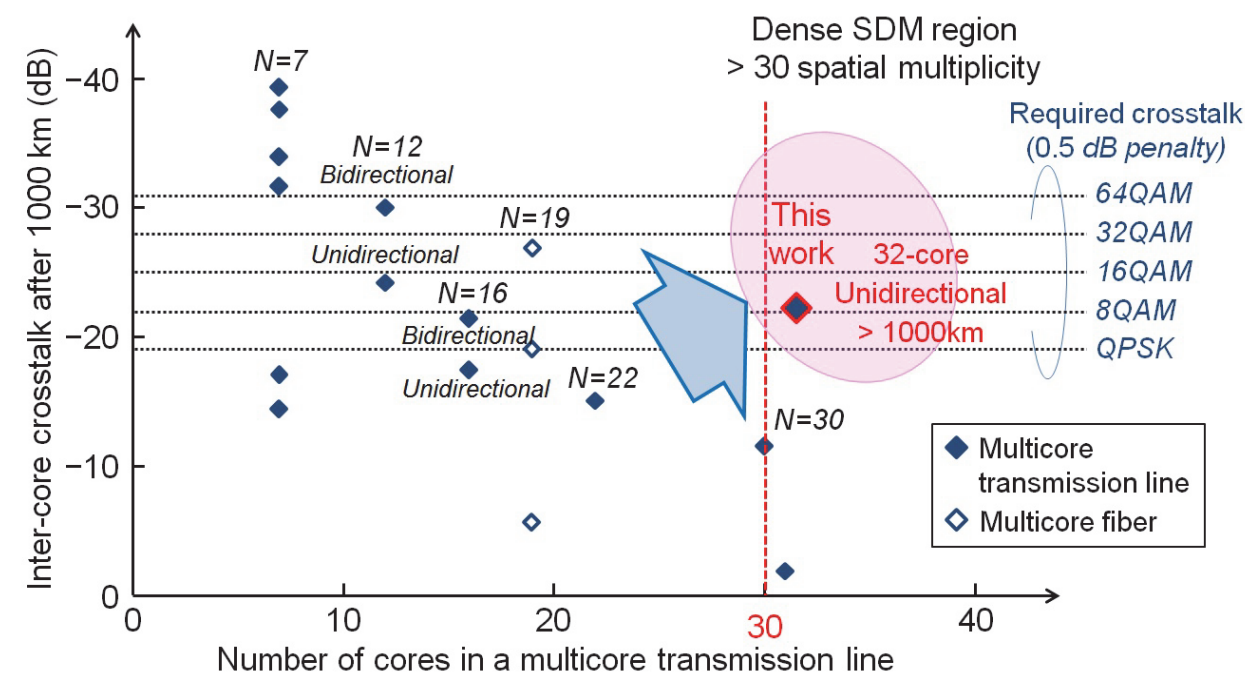

Fig. 4. Crosstalk after 1000-km transmission as a function of the number of core per fiber in a single-mode MCF. The filled and blank plot shows characteristics of multicore transmission line including FI/FO devices, and multicore fiber, respectively. Dotted lines show the crosstalk levels required for various modulation formats assuming $0.5 \mathrm{~dB}$ penalty. 
method involves parallel recirculating loop system with core averaging by core-to-core rotation [9-12,28], without core averaging [17], and with mixing of signals between cores during propagation $[13,14]$. These experiments represent long-distance parallel transmission over each core in an MCF. On the other hand, the method requires $N$ sets of optical components to construct parallel recirculating loops. To date, up to 12 parallel recirculating loops with 12-core MCFs have been demonstrated $[9,28]$.

As an alternative to parallel core transmission, transmission experiments over serially connected cores of an MCF were reported $[29,30]$. In a bi-directional transmission experiment over a 16-core fiber, eight cores were connected in series to transmit in one direction and the remaining eight cores were connected in series to transmit in the opposite direction. This yielded a serially connected bi-directional $880-\mathrm{km}(=55 \mathrm{~km} \times 8$ cores $\times 2$ directions) transmission line [29]. In another experiment, 12 cores of a 12-core MCF were connected in series to construct a span of $552 \mathrm{~km}(=46 \mathrm{~km} \times 12$ cores $)$, and a recirculating loop experiment was conducted with this serially-connected span [30]. The configurations of these experiments are simple and require few optical components. On the other hand, the drawback is that the measurement cannot distinguish the performance of individual cores.

The parallel recirculating loops with core averaging and the serially connected measurement may be a good method to approximate an MCF transmission line when the variation among core is modest, whereas the parallel recirculating loops without core averaging can measure the worst case performance, and is suitable for an MCF transmission line such as a high-core count MCF having variations in loss and crosstalk among cores depending on the core position. To characterize a long-haul MCF transmission line with good degree of approximation, it is favorable to have the ability of measuring performance of each core. However, an MCF having many cores, in particular, those with over several tens of cores, requires massive optical components to construct a full recirculating loop system.

We propose a novel partial recirculating loop system as shown in Figure 5 as an effective method for characterizing long distance transmission performance of an MCF for DSDM transmission. In this experimental setup, we form recirculating loops with part of the cores of an MCF including cores under measurement, and load non-recirculating signals to all other cores of an MCF. The optical power of signal input to each core of the MCF is set at the same value. In the initial experimental setup reported in [22], we constructed five recirculating loops, and configured the transmission line so that the recirculating signals are input to the core under measurement and the four adjacent cores with the same refractive index type in the diagonal position relative to the core under measurement as was shown in Fig. 2 (b) having higher inter-core crosstalk in the MCF. Non-recirculating signals are input to all other cores. With this setup, recirculating signals were loaded to cores that could have larger effect on the core under measurement during propagation in the MCF to approximate a full parallel recirculating loop system. We incorporated 32 channel matrix switches into the transmission line to cross-connect cores of the MCF with the recirculating loops and non-recirculating crosstalk signals, and switched the core connections for each measurement. Suppose that when core \#28 was under measurement, cores $\# 28, \# 12$, \#14, \#26, and \#30 were selected to form recirculating loops \#1 to \#5, respectively, while the remaining 27 cores were loaded with non-recirculating signals. The same operation is to be performed for characterizing other cores.

TABLE I

FEATURE OF LONG DiSTANCE TRANSMISSION EXPERIMENTS OVER AN MCF TRANSMISSION LINE

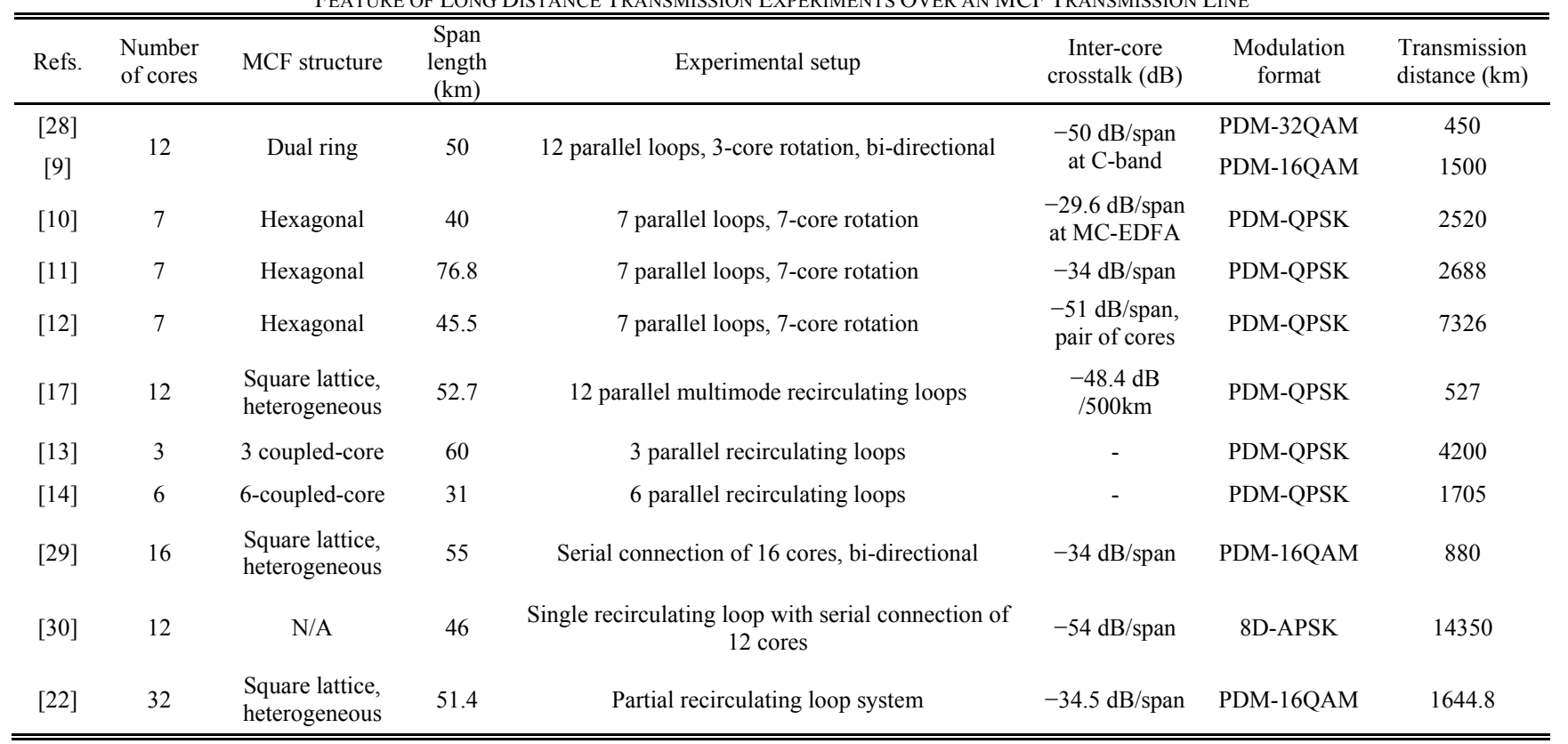




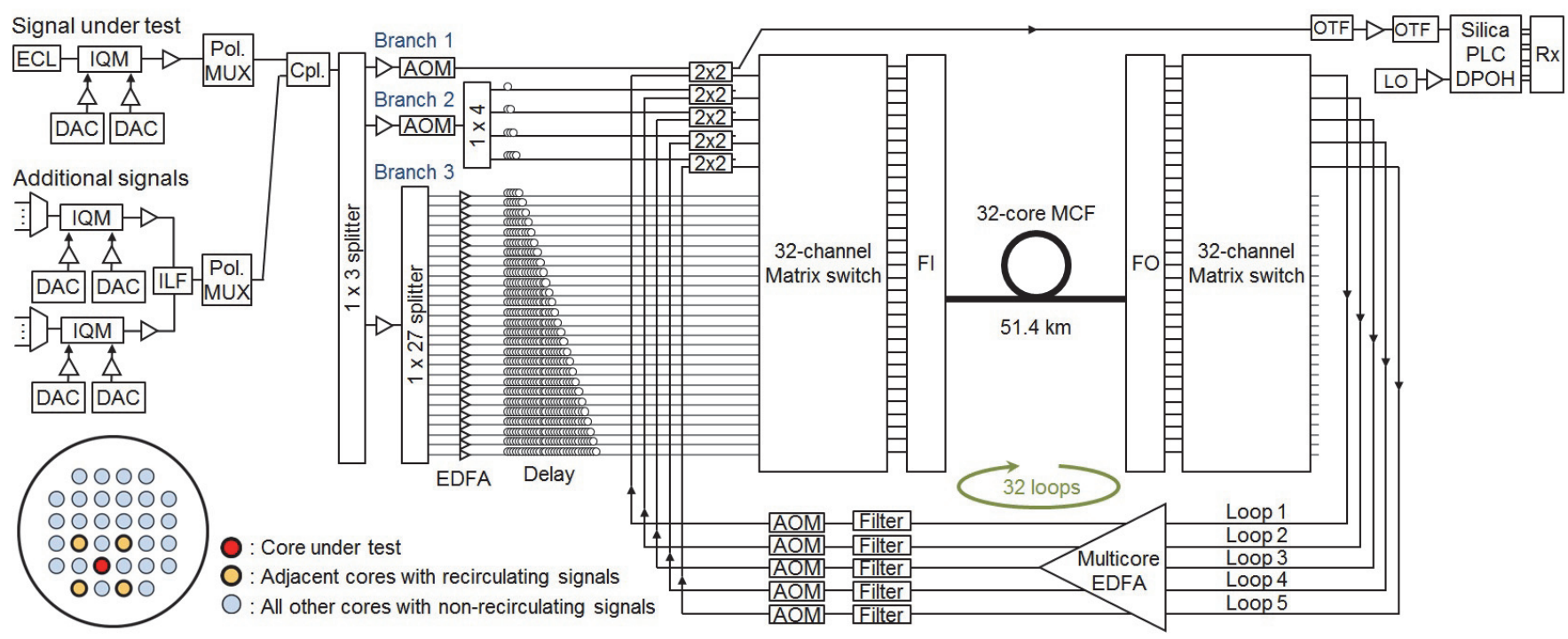

Fig. 5. Experimental setup with a novel partial recirculating loop system.

\section{EXPERIMENTAL SETUP}

We conducted transmission experiments using the low-crosstalk single-mode DSDM transmission line, and the partial recirculating loop system we described in the previous sections.

At the transmitter, the signal under test was generated using a tunable external-cavity laser (ECL) with $\sim 60-\mathrm{kHz}$ linewidth and was modulated by an IQ modulator (IQM). Additional 19 odd and even channels around 1549.1 to $1551.0 \mathrm{~nm}$ were generated using DFB lasers with 2-MHz linewidths and were wavelength multiplexed, separately modulated by IQMs, and combined by a $12.5 / 25 \mathrm{GHz}$ interleave filter. All signals were digitally generated by the IQMs, each driven at 12 Gbaud and reshaped by a root-raised-cosine filter with 0.01 roll-off factor. Different pieces of pseudo-random-binary-sequence (PRBS) of length $2^{23-1}$ were used for each IQM to generate multi-level 16QAM signals. Signals with a frame length of 31250 symbols comprised a payload, $1.63 \%$ overhead for training sequence, and $20 \%$ overhead for forward error correction (FEC). The signal under test, and the remaining 19 wavelength channels were each polarization-division multiplexed by a PDM emulator with a $10 \mathrm{~ns}$ delay, and were combined with a $2 \times 1$ optical coupler. This yielded 12.5-GHz-spaced 20-DWDM 96-Gb/s PDM-16QAM signals.

The signal generated at the transmitter was split into three branches. The first branch was used for the core under measurement in loop \#1, and the second branch was further split into four, which were used to provide recirculating crosstalk signals for loops \#2 to \#5. The third branch was further split into 27, and these signals were used as non-recirculating signals. The 32 signals were relatively delayed by $0, \Delta \mathrm{t}, 2 \Delta \mathrm{t}, \ldots$, and $31 \Delta \mathrm{t}$ with a unit time delay $\Delta \mathrm{t}$ of $20 \mathrm{~ns}$ for decorrelation of signals between the 32 cores. The optical power of the DWDM signals input to the 32-core MCF

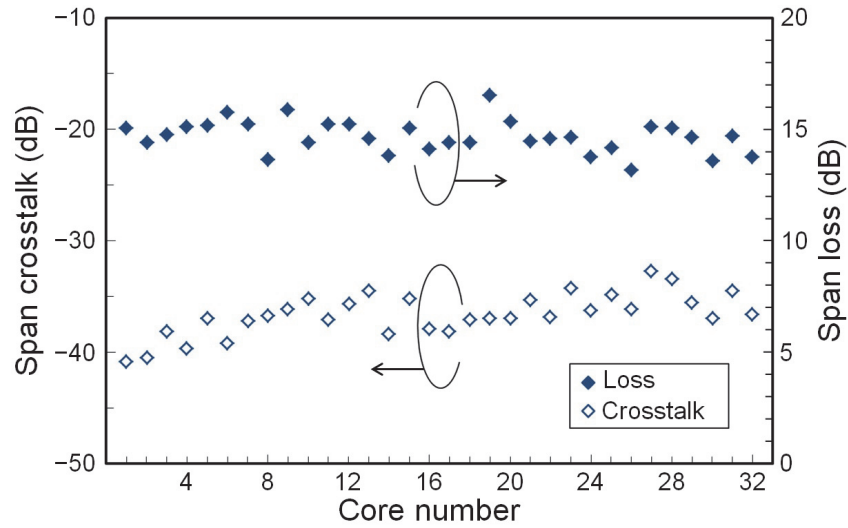

Fig. 6. Span crosstalk and loss of the DSDM transmission line measured at the center wavelength, including 51.4-km 32-core fiber, 32-channel FI/FO devices, and 32-channel matrix switches.

was optimized at $-10 \mathrm{dBm} /$ wavelength/core.

The partial recirculating loop system consisted of the first and second 32-channel matrix switches, a $51.4-\mathrm{km}$ spool of the 32-core fiber, 32-channel FI/FO devices, and five parallel recirculating loops. Signals in the loops were amplified by five channels of a seven-core erbium-doped fiber amplifier (EDFA) [31]. The 32-channel matrix switches were used to select cores and cross-connect the paths of the input and output ports of the transmission line for each measurement as described above.

At the receiver, the signal from the core under test was filtered by a tunable optical filter and input to a planar lightwave circuit (PLC) type dual polarization optical hybrid (DPOH). It was then digitized at $40 \mathrm{GS} / \mathrm{s}$ using a four-channel digital storage oscilloscope and stored in sets of $4 \mathrm{M}$ samples. In the receiver-side offline processing, front-end error correction, chromatic dispersion compensation, and frequency-offset cancellation were first performed. Then, equalization was carried out using 64 T/2-spaced-taps LMS-based $2 \times 2$ frequency domain equalization (FDE) combined with phase 


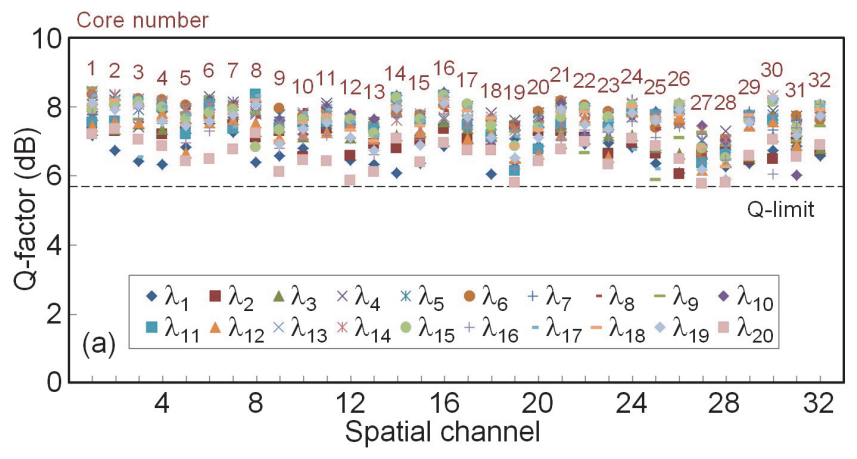

(b)

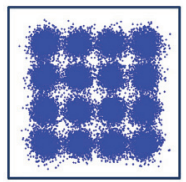

x-pol.

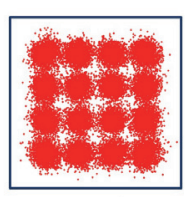

y-pol.

Fig. 7. Measured (a) Q-factors for 20 DWDM $\times 32$ DSDM channels, and (b) constellations of core \#16, wavelength \#11 after $1644.8 \mathrm{~km}$ transmission.

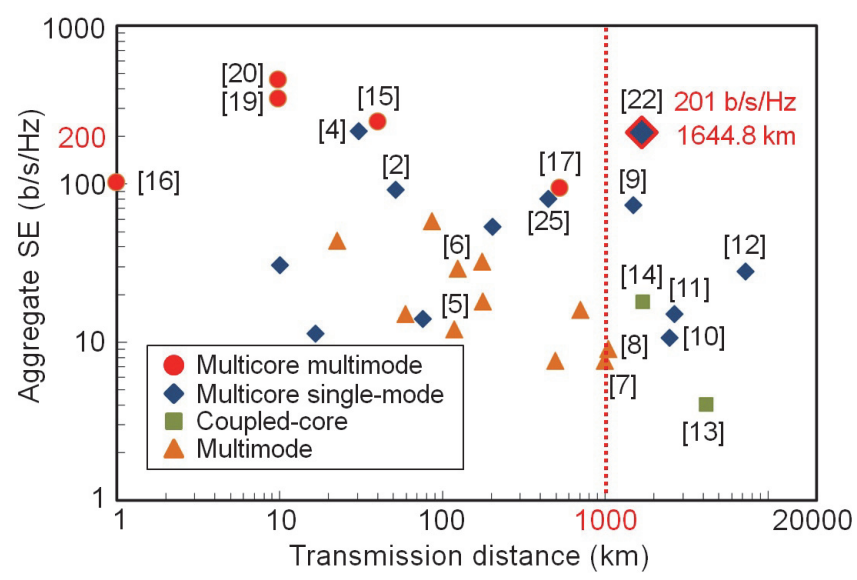

Fig. 8. Aggregate SE versus transmission distance of recent SDM-WDM experiments.

recovery. $0.75 \mathrm{M}$ bits were used to calculate the BERs and Q-factors.

\section{EXPERIMENTAL RESULTS}

\section{1) Characteristics of the 32-core transmission line}

Figure 6 shows the span loss and worst inter-core crosstalk of the 32-core DSDM transmission line including the 51.4-km 32-core fiber, 32-channel FI/FO devices, and the 32-channel matrix switches measured at the center wavelength $\lambda_{11}=1550.128 \mathrm{~nm}$. The span loss for each spatial channel was derived from the power difference between signals input to input port \#1 of the input-side 32-channel matrix switch and signals output from output port \#1 of the output-side 32-channel matrix switch. The inter-core crosstalk was characterized by measuring the power of light output from output port \#1 of the output-side 32-channel matrix switch when light was input only to the core under measurement relative to when light was input to all cores other than that of the core under measurement. The switch settings were changed from core \#1 to \#32 to measure the span loss and inter-core crosstalk for all 32 spatial channels. The span loss was around 1-2 dB higher than that of the 32-core fiber with FI/FO devices. This difference was caused by the insertion loss of the 32-channel matrix switches. The measured inter-core crosstalk of the transmission line with and without the 32-channel matrix switches was almost the same because of the low crosstalk of $<$ $-50 \mathrm{~dB}$ of the 32-channel matrix switches.

\section{2) Q-factor measurement results}

Figure 7(a) shows the measured Q-factors of the 20-DWDM PDM-16QAM signals after $1644.8 \mathrm{~km}$ transmission $(=51.4 \mathrm{~km}$ $\times 32$ loops) as a function of core number. We confirmed that the Q-factors for all $640(20$-DWDM $\times 32$-DSDM) channels were above the Q-limit of 5.7 dB of LDPC convolutional codes using a layered decoding algorithm with $20 \%$ FEC overhead [32]. Figure 7(b) shows an example constellation of the received signals for the center core \#16, wavelength \#11. The net data rate was $78.69 \mathrm{~Gb} / \mathrm{s}$, the $\mathrm{SE}$ was $6.295 \mathrm{~b} / \mathrm{s} / \mathrm{Hz} / \mathrm{core}$, and the aggregate $\mathrm{SE}$ was $201.46 \mathrm{~b} / \mathrm{s} / \mathrm{Hz}$. Figure 8 shows the aggregate $\mathrm{SE}$ versus transmission distance of recent SDM-WDM experiments. The crosstalk-managed high-core count multi-core transmission line allowed us to transmit DSDM signals with high order modulation format over a long distance. We have thus successfully demonstrated a long-haul DSDM transmission over $1600 \mathrm{~km}$ with a high aggregate SE above 200 $\mathrm{b} / \mathrm{s} / \mathrm{Hz}$.

In the above measurement, polarization scrambler was not included in the recirculating loop. To verify the effect of polarization for this experimental setup, a loop synchronous polarization scrambler was inserted in loop \#1 after the amplifier and filter, and Q-factors were measured with and without the polarization scrambler. The measured Q-factors were almost the same, which confirmed that the measurement error due to polarization was negligible for our transmission line.

\section{3) Q-penalty caused by inter-core crosstalk}

To evaluate the effect of inter-core crosstalk on transmission performance, we investigated the Q-penalty caused by inter-core crosstalk. Figure 9 shows the Q-penalty measured after $1644.8 \mathrm{~km}$ transmission at the center wavelength $\lambda_{11}$ versus core number, where the Q-penalty was obtained by measuring the difference of the Q-factors when signal was input only to the core under measurement, and when signals were input to all 32-cores. The inner cores tend to have higher Q-penalty than the outer cores because they are subject to higher crosstalk from larger number of neighboring cores. To observe the effect of inter-core crosstalk on Q-factor more clearly, Figure 10 plots the Q-penalty versus inter-core crosstalk after 32-loops estimated from the span crosstalk shown in Fig. 6. There is strong correlation between the Q-factor and inter-core crosstalk, with Q-penalty increasing linearly as a function of inter-core crosstalk. Highest Q-penalties of 1.2 and $1.0 \mathrm{~dB}$ were observed with cores \#27 and $\# 28$, respectively. If we are to use the core-averaging scheme, 


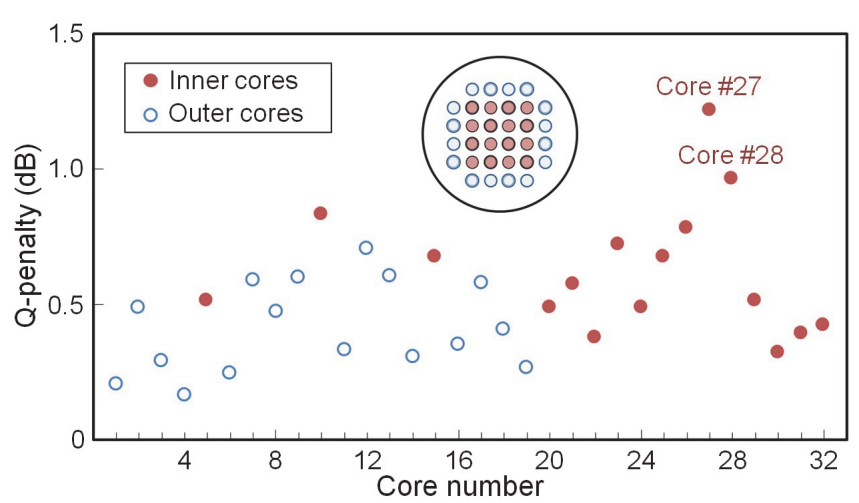

Fig. 9. Measured Q-penalty after $1644.8 \mathrm{~km}$ transmission at the center wavelength versus core number.

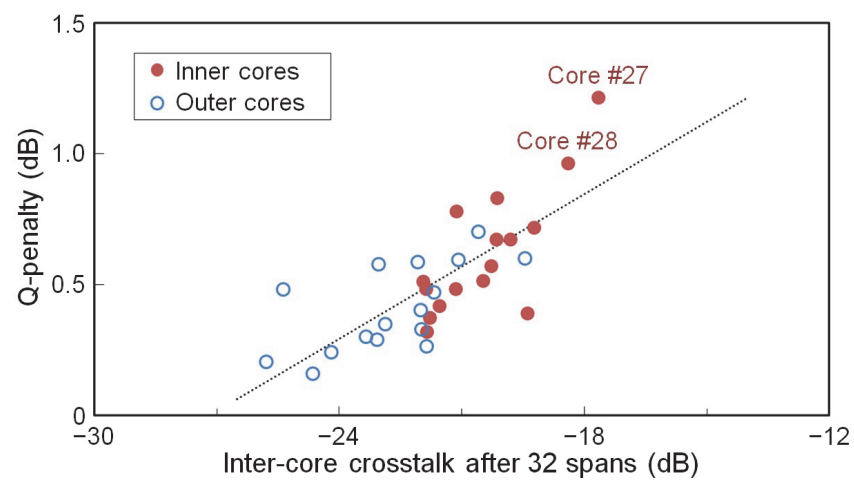

Fig. 10. Correlation between Q-penalty and inter-core crosstalk after 32-loops estimated from the span crosstalk of each core.

the crosstalk after the series of 32-cores will add up to $-21 \mathrm{~dB}$ and will result in a Q-penalty of $0.55 \mathrm{~dB}$. This estimate is 0.65 $\mathrm{dB}$ lower than that of the actually obtained worst Q-penalty of $1.2 \mathrm{~dB}$ in core $\# 27$, thus indicating the significance of characterizing the performance of each core.

Figure 11 shows the measured Q-factor as a function of transmission distance for these two cores \#27 and \#28 with the largest Q-penalties. The blank plots are the Q-factor measured when the signal was input only to the core under measurement and all other 31 cores contained no signal (measurement without inter-core crosstalk). The back-to-back performance of the $96 \mathrm{~Gb} / \mathrm{s}$ PDM-16QAM was approximately $12 \mathrm{~dB}$. Figure 12 shows the system optical signal-to-noise ratio (OSNR) as a function of transmission distance. $50 \mathrm{GHz}$-spaced five WDM continuous wave $(\mathrm{CW})$ light with the launch power equivalent to that of the transmission signal was input to the recirculating loop system. The system OSNR was measured at various loops by an optical spectrum analyzer with $0.1 \mathrm{~nm}$ resolution, and converted to the OSNR of the $12.5 \mathrm{GHz}$-spaced 20-DWDM signals. The Q-factor degradation with transmission distance in Fig. 11 was caused by the OSNR degradation as well as nonlinearity and other impairments of the system.

The filled plots in Fig. 11 are the Q-factor measured when the signal was input to all 32 cores (measurement with inter-core crosstalk). The Q-factor difference between the filled and blank plots at each transmission distance corresponds to the Q-factor penalty caused by the inter-core crosstalk. The figure also indicates that the Q-factor performance over long distances for both cores \#27 and \#28 were similar, although these two cores had different refractive index profiles. This result confirms that the heterogeneous design has no detrimental effect on the transmission performance, and is useful for extending reach by crosstalk reduction.

The dotted line shows the Q-factor limit of $5.7 \mathrm{~dB}$ for $20 \%$ FEC overhead [32]. By implementing the latest digital signal processing, longer distance is possible. Suppose we use $25.5 \%$ FEC overhead [33], the Q-factor limit will relax to $5 \mathrm{~dB}$, and yield approximately $10 \%$ increase of transmission distance with a slightly reduced aggregate SE of $192.63 \mathrm{~b} / \mathrm{s} / \mathrm{Hz}$.

\section{4) Recirculating and non-recirculating crosstalk signals}

In standard long distance MCF transmission experiments, recirculating signals are loaded to all cores, and transmitted together with the core under measurement to approximate transmission over a long transmission line. This is under the assumption that the transmission performance may differ between recirculating and non-recirculating crosstalk signals. To approximate a full parallel recirculating loop system, we have loaded recirculating signals to four adjacent cores in the diagonal position relative to the core under measurement which is assumed to affect the core under measurement the most during transmission due to inter-core crosstalk.

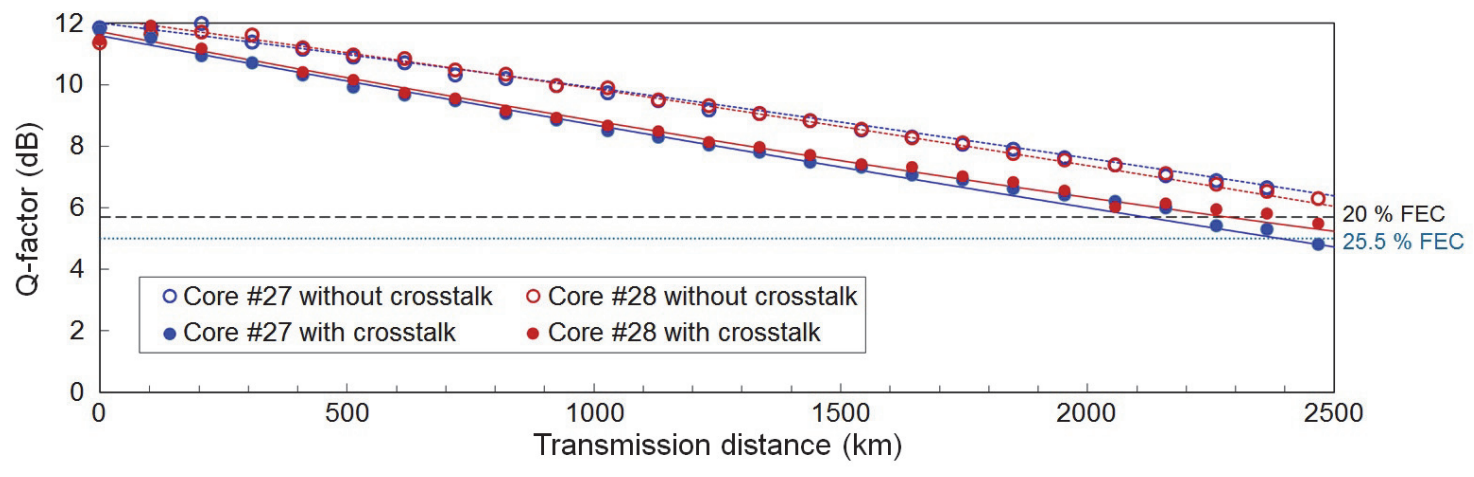

Fig. 11. Measured Q-factor as a function of transmission distance for cores \#27 and \#28 with and without inter-core crosstalk. A $5.7 \mathrm{~dB}$ Q-limit of $20 \%$ FEC overhead was employed in this transmission experiment. 


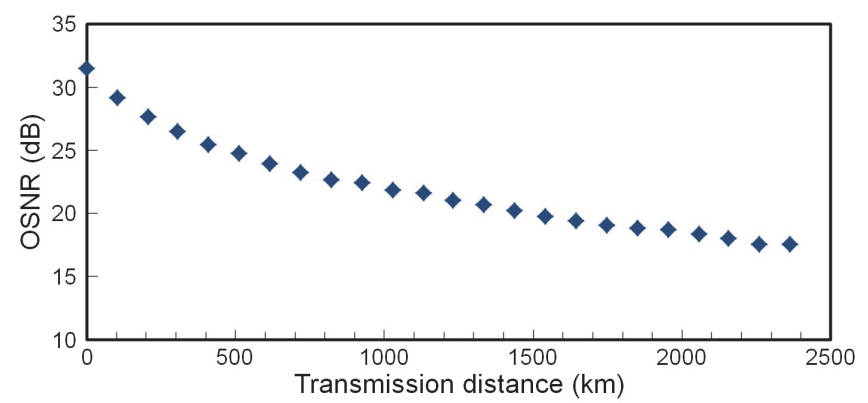

Fig. 12. System OSNR as a function of transmission distance.

In this section, we compare the difference of Q-factors when the neighboring cores are changed from recirculating signals to non-recirculating signals. The type of signals loaded to cores was controlled by changing the port connections of the 32-channel matrix switches. Figure 13 shows the signal loading pattern including, (a) recirculating signals loaded to four diagonal cores, (b) non-recirculating signals loaded to four diagonal cores, (c) non-recirculating signals loaded to four nearest cores, (d) recirculating signals loaded to four nearest cores, (e) recirculating signals loaded to four diagonal cores and non-recirculating signals loaded to all other 27 cores (same crosstalk loading pattern as the Q-factor measurement in Fig. 7), and (e) non-recirculating signals loaded to all other 31 cores. Recirculating signal for loop \#1 was always loaded to the core under measurement.

Figures 14(a) and (b) shows the Q-factor difference as a function of transmission distance for core \#27 and \#28, respectively, measured at the center wavelength $\lambda_{11}$. The OSNR level of the input signal was $31.5 \mathrm{~dB}$, and that after 32 loops was $19.4 \mathrm{~dB}$ (Fig. 12). The Q-factor difference designated as "diagonal cores" are the difference of the measured Q-factors when signals were loaded into five cores with the pattern in Fig. 13 (a) between that in Fig. 13 (b). Similarly, those designated as "nearest cores" are the difference of the measured Q-factors when signals were loaded into five cores with the pattern in Fig. 13 (c) between that in Fig. 13 (d). The difference of the measured Q-factors when signals were loaded into all the 32 cores with the pattern in Fig. 13 (e) between that in Fig. 13 (f) are designated as "all cores". With various distances, the Q-factor difference was within measurement error. This result implies that in our experimental setup, the transmission performance is the same regardless of the neighboring cores being recirculating or non-recirculating crosstalk signals. The conditions necessary for such state include managing the experimental setup to launch all cores with uniform signal input power, and to maintain similar overall passband spectrum for the recirculating and non-recirculating crosstalk signals.

\section{CONCLUSION}

We have presented the experimental demonstration of a long-haul DSDM transmission over a 32-core single-mode transmission line. We have provided the characteristics of the novel low-crosstalk heterogeneous 32-core fiber and the configuration of the novel partial recirculating loop system.

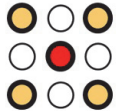

(a)

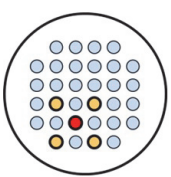

(e)

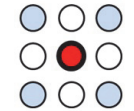

(b)

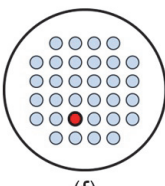

(f)

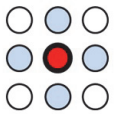

(c)

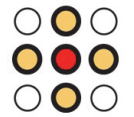

(d)
Fig. 13. Crosstalk loading patterns employed to compare the difference of the effect of recirculating and non-recirculating crosstalk signals on the core under measurement. Recirculating signals from loop \#1 was loaded to core under test, various signals was input to other cores including (a) recirculating signals loaded to four diagonal cores, (b) non-recirculating signals loaded to four diagonal cores, (c) recirculating signals loaded to four nearest cores, (d) non-recirculating signals loaded to four nearest cores, (e) recirculating signals loaded to four diagonal cores and non-recirculating signals loaded to all other 27 cores, and (e) non-recirculating signals loaded to all other 31 cores.
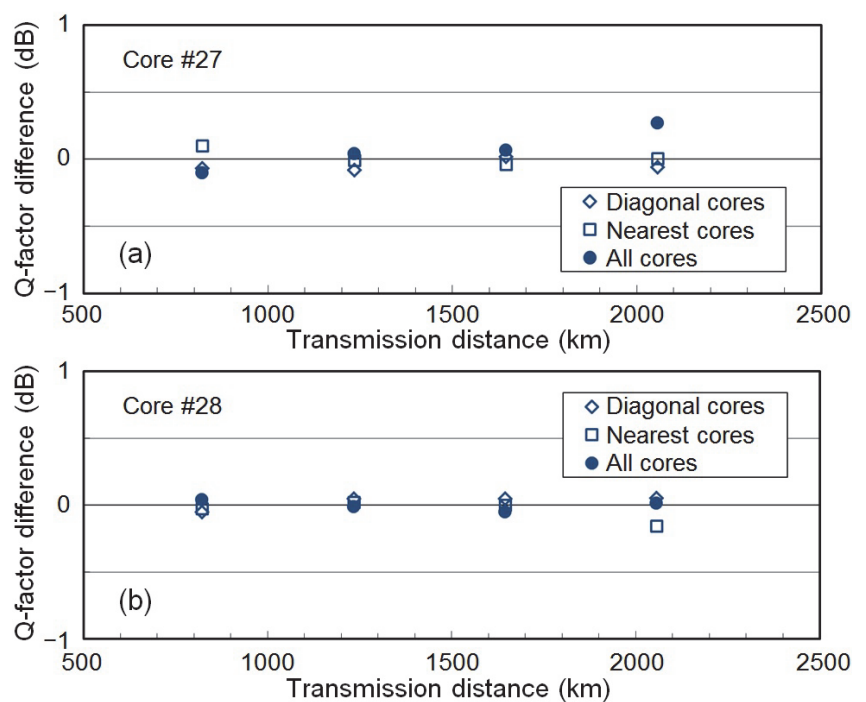

Fig. 14. Difference of measured Q-factors with recirculating and non-recirculating crosstalk signals for (a) core \#27 and (b) core \#28. The "diagonal cores", "nearest cores", and "all cores" show difference of Q-factors between crosstalk loading patterns in Figs. 13(a) and (b), Figs. 13(c) and (d), and Figs. 13(e) and (f), respectively.

The low span crosstalk of $-34.5 \mathrm{~dB} / 51.4 \mathrm{~km}$ realized by our fiber design and fabrication technology enabled us to achieve long-haul DSDM unidirectional transmission over a thousand $\mathrm{km}$ with over 30 spatial multiplicity for the first time. The 12.5GHz-spaced 20-DWDM, PDM-16QAM signals over 32-cores yielded a high aggregate spectral efficiency of 201.46 $\mathrm{b} / \mathrm{s} / \mathrm{Hz}$. The transmission distance of $1644.8 \mathrm{~km}$ equivalent to 32 loops of the $51.4 \mathrm{~km}$ span is more than three times longer for DSDM transmission with over 30 spatial multiplicity, and around three times larger spatial multiplicity per direction for long-haul transmission exceeding $1000 \mathrm{~km}$. In addition, we investigated the effect of crosstalk on Q-penalty utilizing the partial recirculating loop system, and showed that the Q-penalty had strong correlation with inter-core crosstalk, and depended on core allocation. Moreover, we examined the validity of the measurement using the partial recirculating loop 
system. As an alternative to conventional multicore recirculating loop measurement, our proposed partial recirculating loop system is an effective means for characterizing long distance transmission performance of multicore transmission lines, in particular, when the number of cores is large and when inter-core crosstalk depend on core configuration.

\section{ACKNOWLEDGMENTS}

Part of this research utilized results from the EU-Japan coordinated R\&D project on "Scalable And Flexible optical Architecture for Reconfigurable Infrastructure (SAFARI)" commissioned by the Ministry of Internal Affairs and Communications (MIC) of Japan and EC Horizon 2020, and research commissioned by the National Institute of Information and Communications Technology (NICT) of Japan.

\section{REFERENCES}

[1] T. Morioka, "New generation optical infrastructure technologies: "EXAT Initiative" towards 2020 and beyond," in Proc. OECC, FT4, 2009.

[2] H. Takara, A. Sano, T. Kobayashi, H. Kubota, H. Kawakami, A. Matsuura, Y. Miyamoto, Y. Abe, H. Ono, K. Shikama, Y. Goto, K Tsujikawa, Y. Sasaki, I. Ishida, K. Takenaga, S. Matsuo, K. Saitoh, M. Koshiba, and T. Morioka, "1.01-Pb/s (12 SDM/222 WDM/456 Gb/s) crosstalk-managed transmission with $91.4-\mathrm{b} / \mathrm{s} / \mathrm{Hz}$ aggregate spectral efficiency," in Proc. ECOC, Th.3.C.1, 2012.

[3] D. Qian, E. Ip, M.-F. Huang, M.-J. Li, A. Dogariu, S. Zhang, Y. Shao, Y.-K. Huang, Y. Zhang, X. Cheng, Y. Tian, P. N. Ji, A. Collier, Y. Geng, J. Liñares, C. Montero, V. Moreno, X. Prieto, and T. Wang, " $1.05 \mathrm{~Pb} / \mathrm{s}$ transmission with $109 \mathrm{~b} / \mathrm{s} / \mathrm{Hz}$ spectral efficiency using hybrid single- and few-mode cores," in Proc. FiO, FW6C.3, 2012.

[4] B. J. Puttnam, R. S. Luís, W. Klaus, J. Sakaguchi, J.-M. Delgado Mendinueta, Y. Awaji, N. Wada, Y. Tamura, T. Hayashi, M. Hirano, and J. Marciante, "2.15 Pb/s transmission using a 22 core homogeneous single-mode multi-core fiber and wideband optical comb," in Proc. ECOC, PDP.3.1, 2015.

[5] V. A. J. M. Sleiffer, Y. Jung, V. Veljanovski, R. G. H. van Uden, M. Kuschnerov, Q. Kang, L. Grüner-Nielsen, Y. Sun, D. J. Richardson, S. Alam, F. Poletti, J. K. Sahu, A. Dhar, H. Chen, B. Inan, A. M. J. Koonen, B. Corbett, R. Winfield, A. D. Ellis, and H. de Waardt, "73.7 Tb/s $(96 \times 3 \times 256-\mathrm{Gb} / \mathrm{s})$ mode-division-multiplexed DP-16QAM transmission with inline MM-EDFA," in Proc. ECOC, Th.3.C.4, 2012.

[6] R. Ryf, H. Chen, N. K. Fontaine, A. M. Velazquez-Benitez, Jose Antonio-Lopez, C. Jin, B. Huang, M. Bigot-Astruc, D. Molin, F. Achten, P. Sillard, and R. Amezcua-Correa, "10-mode mode-multiplexed transmission over 125-km single-span multimode fiber," in Proc. ECOC, PDP.3.3, 2015.

[7] E. Ip, M.-J. Li, K. Bennett, Y.-K. Huang, A. Tanaka, A. Korolev, K.

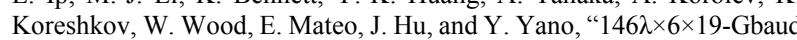
wavelength- and mode-division multiplexed transmission over $10 \times 50-\mathrm{km}$ spans of few-mode fiber with a gain-equalized few-mode EDFA," in Proc. OFC/NFOEC, PDP5A.2, 2013

[8] R. Ryf, M. Esmaeelpour, N. K. Fontaine, H. Chen, A. H. Gnauck, R.-J. Essiambre, J. Toulouse, Y. Sun, and R. Lingle, Jr., "Distributed Raman amplification based transmission over 1050-km few-mode fiber," in Proc. ECOC, Tu.3.2.3, 2015.

[9] T. Kobayashi, H. Takara, A. Sano, T. Mizuno, H. Kawakami, Y. Miyamoto, K. Hiraga, Y. Abe, H. Ono, M. Wada, Y. Sasaki, I. Ishida, K. Takenaga, S. Matsuo, K. Saitoh, " $2 \times 344 \mathrm{~Tb} / \mathrm{s}$ propagation-direction interleaved transmission over $1500-\mathrm{km} \mathrm{MCF}$ enhanced by multicarrier full electric-field digital back-propagation," in Proc. ECOC, PD3.E.4, 2013.

[10] K. Takeshima, T. Tsuritani, Y. Tsuchida, K. Maeda, T. Saito, K. Watanabe, T. Sasa, K. Imamura, R. Sugizaki, K. Igarashi, I. Morita, and M. Suzuki, "51.1-Tbit/s MCF transmission over 2,520 km using cladding pumped 7-core EDFAs," in Proc. OFC, W3G.1, 2015.
[11] S. Chandrasekhar, A. H. Gnauck, Xiang Liu, P. J. Winzer, Y. Pan, E. C. Burrows, T. F. Taunay, B. Zhu, M. Fishteyn, M. F. Yan, J. M. Fini, E.M. Monberg, and F. V. Dimarcello, "WDM/SDM transmission of $10 \mathrm{x}$ 128-Gb/s PDMQPSK over 2688-km 7-core fiber with a per-fiber net aggregate spectral-efficiency distance product of $40,320 \mathrm{~km} \cdot \mathrm{b} / \mathrm{s} / \mathrm{Hz}, "$ Opt. Exp., vol. 20, no. 2, pp. 706-711, Jan. 2012.

[12] K. Igarashi, T. Tsuritani, I. Morita, Y. Tsuchida, K. Maeda, M. Tadakuma, T. Saito, K. Watanabe, K. Imamura, R. Sugizaki, and M. Suzuki, "1.03-Exabit/s $\times$ km super-Nyquist-WDM transmission over 7,326-km seven-core fiber," in Proc. ECOC, PD3.E.3, 2013.

[13] R. Ryf, R.-J. Essiambre, A. H. Gnauck, S. Randel, M. A. Mestre, C. Schmidt, P. J. Winzer, R. Delbue, P. Pupalaikis, A. Sureka, T. Hayashi, T. Taru, and T. Sasaki, "Space-division multiplexed transmission over 4200-km 3-core microstructured fiber," in Proc. OFC/NFOEC, PDP5C.2, 2012.

[14] R. Ryf, N. K. Fontaine, B. Guan, R.-J. Essiambre, S. Randel, A. H. Gnauck, S. Chandrasekhar, A. Adamiecki, G. Raybon, B. Ercan, R. P. Scott, S. J. Ben Yoo, T. Hayashi, T. Nagashima, and T. Sasaki, "1705-km transmission over coupled-core fibre supporting 6 spatial modes," in Proc. ECOC, PD.3.2, 2014.

[15] T. Mizuno, T. Kobayashi, H. Takara, A. Sano, H. Kawakami, T. Nakagawa, Y. Miyamoto, Y. Abe, T. Goh, M. Oguma, T. Sakamoto, Y. Sasaki, I. Ishida, K. Takenaga, S. Matsuo, K. Saitoh, and T. Morioka, "12-core $\times 3$-mode dense space division multiplexed transmission over 40 km employing multi-carrier signals with parallel MIMO equalization," in Proc. OFC, Th5B.2, 2014.

[16] R. G. H. van Uden, R. A. Correa, E. A.-Lopez, F. M. Huijskens, G. Li, A. Schulzgen, H. de Waardt, A. M. J. Koonen, and C. M. Okonkwo, "1 km hole-assisted few-mode multi-core fiber 32QAM WDM transmission," in Proc. ECOC, Mo.3.3.4, 2014.

[17] K. Shibahara, T. Mizuno, H. Takara, A. Sano, H. Kawakami, D. Lee, Y. Miyamoto, H. Ono, M. Oguma, Y. Abe, T. Kobayashi, T. Matsui, R. Fukumoto, Y. Amma, T. Hosokawa, S. Matsuo, K. Saito, H. Nasu, and T. Morioka, "Dense SDM (12-core $\times 3$-mode) transmission over $527 \mathrm{~km}$ with 33.2-ns mode-dispersion employing low-complexity parallel MIMO frequency-domain equalization," in Proc. OFC, Th5C.3, 2015.

[18] J. Sakaguchi, W. Klaus, J.-M. D. Mendinueta, B. J. Puttnam, R. S. Luis, Y. Awaji, N. Wada, T. Hayashi, T. Nakanishi, T. Watanabe, Y. Kokubun, T. Takahata, and T. Kobayashi, "Realizing a 36-core, 3-mode fiber with 108 spatial channels," in Proc. OFC, Th5C.2, 2015.

[19] K. Igarashi, D. Souma, Y. Wakayama, K. Takeshima, Y. Kawaguchi, T. Tsuritani, and I. Morita, "114 space-division-multiplexed transmission over 9.8-km weakly-coupled-6-mode uncoupled-19-core fibers," in Proc. $O F C$, Th5C.4, 2015 .

[20] D. Soma, K. Igarashi, Y. Wakayama, K. Takeshima, Y. Kawaguchi, N. Yoshikane, T. Tsuritani, I. Morita, and M. Suzuki, "2.05 peta-bit/s super-Nyquist-WDM SDM transmission using 9.8-km 6-mode 19-core fiber in full C band," in Proc. ECOC, PDP.3.2, 2015.

[21] T. Sakamoto, T. Matsui, K. Saitoh, S. Saitoh, K. Takenaga, T. Mizuno, Y. Abe, K. Shibahara, Y. Tobita, S. Matsuo, K. Aikawa, S. Aozasa, K. Nakajima, and Y. Miyamoto, "Low-loss and low-DMD few-mode multi-core fiber with highest core multiplicity factor," in Proc. OFC, Th5A.2, 2016.

[22] T. Mizuno, K. Shibahara, H. Ono, Y.Abe, Y. Miyamoto, F. Ye, T. Morioka, Y. Sasaki, Y. Amma, K. Takenaga, S. Matsuo, K. Aikawa, K. Saitoh, Y. Jung, D. J. Richardson, K. Pulverer, M. Bohn, and M. Yamada, "32-core dense SDM unidirectional transmission of PDM-16QAM signals over $1600 \mathrm{~km}$ using crosstalk-managed single-mode heterogeneous multicore transmission line," in Proc. OFC, Th5C.3, 2016.

[23] S. Matsuo, K. Takenaga, Y. Sasaki, Y. Amma, S. Saito, K. Saitoh, T. Matsui, K. Nakajima, T. Mizuno, H. Takara, Y. Miyamoto, and T. Morioka, "High-spatial-multiplicity multicore fibers for future dense space-division-multiplexing systems," IEEE J. Lightwv. Technol., vol. 34 , no. 6, pp. 1464-1475, March 2016.

[24] K. Aikawa, Y. Sasaki, Y. Amma, K. Takenaga, S. Matsuo, K. Saitoh, T. Morioka, Y. Miyamoto, "High core count single-mode multicore fiber for dense space division multiplexing," in Proc. IEEE Photonics Society Summer Topicals Meeting Series, WE2.2, 2016.

[25] Y. Tottori, T. Kobayashi, and M. Watanabe, "Low loss optical connection module for seven-core multicore fiber and seven single-mode fibers," IEEE Photon. Technol. Lett., vol. 24, no. 21, pp. 1926-1928, Nov. 2012.

[26] P. Winzer, A. Gnauck, A. Konczykowska, F. Jorge, and J.-Y. Dupuy, "Penalties from in-band crosstalk for advanced optical modulation formats," in Proc. ECOC, Tu.5.B.7, 2011. 
[27] A. Sano, H. Takara, T. Kobayashi, and Y. Miyamoto, "Crosstalk-managed high capacity long haul multicore fiber transmission with propagation-direction interleaving," IEEE J. Lightwv. Technol., vol. 32, no. 16, pp. 2771-2779, Aug. 2014

[28] A. Sano, H. Takara, T. Kobayashi, H. Kawakami, H. Kishikawa, T. Nakagawa, Y. Miyamoto, Y. Abe, H. Ono, K. Shikama, M. Nagatani, T. Mori, Y. Sasaki, I. Ishida, K. Takenaga, S. Matsuo, K. Saitoh, M. Koshiba, M. Yamada, H. Masuda, and T. Morioka, "409-Tb/s + 409-Tb/s crosstalk suppressed bidirectional MCF transmission over $450 \mathrm{~km}$ using propagation-direction interleaving," Opt. Exp., vol. 21, no. 14, pp. 16777-16783, July 2013.

[29] M. Arikawa, T. Ito, E. L. T. de Gabory, and K. Fukuchi, "Crosstalk reduction using bidirectional signal assignment over square lattice structure 16-core fiber for gradual upgrade of SSMF-based lines," in Proc. ECOC, Th.1.2.3, 2015.

[30] A. Turukhin, O. V. Sinkin, H. G. Batshon, H. Zhang, Y. Sun, M. Mazurczyk, C. R. Davidson, J.-X. Cai, M. A. Bolshtyansky, D. G. Foursa, and A. Pilipetskii, "105.1 Tb/s power-efficient transmission over 14,350 km using a 12-core fiber," in Proc. OFC, Th4C.1, 2016.

[31] K. Takenaga, K. Ichii, S. Matsuo, Y. Abe, H. Ono, M. Yamada, and H. Masuda, "Multicore EDF optimized for remotely pumped amplification system over multicore fiber," in Proc. OECC/PS, TuS1-2, 2013.

[32] D. Chang, F. Yu, Z. Xiao, N. Stojanovic, F. N. Hauske, Y. Cai, C. Xie, L. $\mathrm{Li}, \mathrm{X}$. Xu, Q. Xiong, "LDPC convolutional codes using layered decoding algorithm for high speed coherent optical transmission," in Proc OFC/NFOEC, OW1H.4, 2012

[33] K. Sugihara, Y. Miyata, T. Sugihara, K. Kubo, H. Yoshida, W. Matsumoto, and T. Mizuochi, "A Spatially-coupled Type LDPC Code with an NCG of $12 \mathrm{~dB}$ for Optical Transmission beyond $100 \mathrm{~Gb} / \mathrm{s}$," in Proc. OFC/NFOEC, OM2B.4, 2013.

Takayuki Mizuno (M’04) received the B.E. degree in applied physics, M.E. degree in crystalline materials science, and Dr. Eng. degree in quantum engineering, all from Nagoya University, Nagoya, Japan, in 1998, 2000, and 2007, respectively.

In 2000, he joined NTT Photonics Laboratories, NTT Corporation, Japan, where he was involved in the research and development of silica planar lightwave circuit optical waveguide devices, including arrayed-waveguide gratings, Mach-Zehnder interferometer-based filters and switches, and digital coherent demodulators for advanced modulation formats. He is currently a Senior Research Engineer at NTT Network Innovation Laboratories, NTT Corporation, Kanagawa, Japan. He is the author and/or co-author of more than 80 journal and international conference papers, and holds over 30 granted patents. His present research interests include space division multiplexed transmission technology for ultra-high capacity optical transport systems.

Dr. Mizuno is a Member of the Institute of Electronics, Information, and Communication Engineers (IEICE) of Japan.

Kohki Shibahara received the B.S. in physics and M.S. degrees in geophysics from Kyoto University, Kyoto, Japan, in 2008, and 2010, respectively.

Since 2010, he has been with NTT Network Innovation Laboratories, Yokosuka, Kanagawa, Japan. His current research interests include spatial division multiplexing transmission systems and advanced MIMO signal processing. He is a member of the Institute of Electronics, Information and Communication Engineers (IEICE) of Japan.

Feihong Ye received his B.E. degree from South China University of Technology, Guangzhou, China, in 2005. He received his M.Sc. degree in IC Design Engineering from the Hong Kong University of Science and Technology, in 2010, and double degrees (Scuola Superiore Sant'Anna, Pisa, Italy \& Osaka University, Japan) from Erasmus Mundus program in MAsters on Photonic NETworks engineering (MAPNET), in 2012. He received his Ph.D. degree on space-division multiplexing for ultrahigh-capacity photonic transport beyond Pbit/s from Technical University of Denmark in 2016.

Yusuke Sasaki was born in Chiba, Japan, in 1986. He received the B.E. and M.E. degrees in electrical engineering from the Tokyo Institute of Technology, Tokyo, Japan, in 2008 and 2010, respectively.

In 2010, he joined Fujikura, Ltd., Chiba, Japan, and he has been involved in research and development of multicore fibers. He is a Member of the Institute of Electronics, Information and Communication Engineers (IEICE) of Japan.
Yoshimichi Amma received the B.S. degree in 2010 and M.S. degree in mechanical engineering from Yokohama National University, Kanagawa, Japan, in 2012.

In 2012, he joined Fujikura, Ltd., Chiba, Japan, where he has been involved in research and development of multicore fibers. He has attended 10 conferences. Mr. Amma is a Member of the Institute of Electronics, Information and Communication Engineers of Japan.

Katsuhiro Takenaga was born in Tochigi, Japan, in 1976. He received the B.S degree from Shinshu University, Nagano, Japan, and the M.S. degree from Hokkaido University, Sapporo, Japan, in 1999 and 2001, both in physics.

In 2001, he joined Fujikura, Ltd., Chiba, Japan, where he has been involved in research and development of optical fibers. He is a Member of the Institute of Electronics, Information and Communication Engineers of Japan.

Yongmin Jung (M'13) was born in Jindo, South Korea. He received the B.S. degree in Physics in 2003 from Chung-Ang University, Korea and the M.S. and Ph.D. degree in engineering of information and communications from Gwangju Institute of Science and Technology (GIST), Korea, in 2004 and 2008, respectively.

$\mathrm{He}$ joined Optoelectronics Research Centre (ORC), University of Southampton in U.K. in March 2008 and is currently a Senior Research Fellow. His main research interests are the multimode fiber amplifiers and mode division multiplexed transmission over few mode fibers.

Klaus Pulverer received the Ph.D. degree in mathematical physics from the University of Oxford, Oxford, U.K. After several years of research in mathematical modeling and numerical simulation at the Technical University of Munich, he joined Siemens and later Nokia Siemens Networks and Coriant to work in the fields of communication protocols, next generation networks architectures and optical access. He has been active in standardization since 2002, until 2008 as co-chair of architecture in ETSI TISPAN and afterward in ITU-T and FSAN for optical access.

Hirotaka Ono (M'96-SM'15) received the B.S., M.S., and Ph.D. degrees in applied physics from Tohoku University, Sendai, Japan, in 1993, 1995, and 2004, respectively.

He joined the NTT Laboratories, Tokai, Ibaraki, Japan, in 1995. He was also a Visiting Research Fellow with the Optoelectronics Research Centre, University of Southampton, Southampton, U.K., from 2005 to 2006. He has been involved in research on optical fiber amplifiers, including L- and S-band erbium-doped fiber amplifiers. He has also undertaken research on highly nonlinear fiber devices, photonic crystal fibers, and wavelength-division multiplexing transmission systems. His current research interests include fiber and waveguide devices, including optical amplifiers, used for space-division multiplexing systems.

Dr. Ono is a Member of the Institute of Electronic, Information and Communication Engineers of Japan and the Japan Society of Applied Physics.

Yoshiteru Abe received the B.E. degree in electrical engineering, the M.E. degree in electronic device engineering, and the Dr. Eng degree in electrical engineering from Kyushu University, Fukuoka, Japan, in 1996, 1998, and 2005, respectively.

In 1998, he joined the Nippon Telegraph and Telephone Corporation Optoelectronics Laboratories, Ibaraki, Japan. He is currently with the NTT Device Technology Laboratories, NTT Corporation, Atsugi, Kanagawa, Japan. His research interest includes optical fiber connectors. He is a Member of the Institute of Electronics, Information and Communication Engineers of Japan.

Makoto Yamada (SM'14) received the B.S., M.E., and Ph.D. degrees in electrical engineering from the Technical University of Nagaoka, Niigata, Japan, in 1983, 1985, and 1998, respectively.

In 1985, he joined the NTT Laboratories, where he was involved in research on guided-wave optical devices. Since 1989, he has been involved in research on optical fiber amplifiers. In 2008, he joined Osaka Prefecture University, Sakai, Japan, where since 2013, has been a Professor. His research interests include design and control for optical amplifiers and other components in 
optical networks. He is a Senior Member of the Institute of Electronics, Information and Communication Engineers.

Kunimasa Saitoh (S'00-M'01) received the B.S., M.S., and Ph.D. degrees in electronic engineering from Hokkaido University, Sapporo, Japan, in 1997 1999, and 2001, respectively.

From 1999 to 2001, he was a Research Fellow of the Japan Society for the Promotion of Science. From 2001 to 2005, he was a Research Associate with the Graduate School of Engineering, Hokkaido University. From 2005 to 2013, he was an Associate Professor at Graduate School of Information Science and Technology, Hokkaido University, and in 2013, he became a Professor there. He has been involved in research on fiber optics, nano-photonics, integrated optical devices, and computer-aided design and modeling of guided-wave devices. He is the author of more than 170 research papers in refereed international journals and more than 210 refereed international conference presentations.

Dr. Saitoh is a Member of the Optical Society of America (OSA), and the Institute of Electronics, Information and Communication Engineers (IEICE) From 2009 to 2010, he served as a Secretary/Treasurer of the IEEE Sapporo Section. He received the Excellent Paper Award and the Young Scientist Award from the IEICE, in 1999 and 2002, respectively, the Young Scientists' Prize of sthe Commendation for Science and Technology from the Ministry of Education, Culture, Sports, Science, and Technology (MEXT), Government of Japan in 2008, and the JSPS Prize from the Japan Society for the Promotion of Science in 2015.

Shoichiro Matsuo (M'11) received the B.E. and M.E. degrees in electrical engineering from Kyushu University, Fukuoka, Japan, in 1988 and 1990, and the $\mathrm{Ph} . \mathrm{D}$. degree in production and information science from Utsunomiya University, Tochigi, Japan, in 2008, respectively.

He has been with Fujikura, Ltd., Japan, since 1990, focusing on the research and development of transmission fibers for long-haul networks and FTTH networks as well as rare-earth-doped fibers and photonic bandgap fibers, and the manufacturing technology for these optical fibers. He was the General Manager of Laboratory, Fujikura, Ltd., from April 2013 to October 2015. He is currently the General Manager of both the Optical Fiber Development Department and the Suzuka Optical Fiber Production Department, Fujikura Ltd.

Dr. Matsuo is a Member of the Optical Society of America, the Japanese Society of Applied Physics, and the Institute of Electronics, Information and Communication Engineers.

Kazuhiko Aikawa received the B.S. degree in applied chemistry from Keio University, Japan, in 1990, and the $\mathrm{PhD}$ degree in production and information science from Utsunomiya University, Japan, in 2010.

He joined Fujikura Ltd. in 1990 and was working on specialty optical fibers and optical components. Now, he is the general manager of Optical Communication Research Department in Advanced Technology Laboratory, Fujikura Ltd.

Marc Bohn received the Dipl.Ing. degree in electrical engineering and the $\mathrm{Ph} . \mathrm{D}$. degree from the University of Kiel, Chair for Communications, Kiel, Germany, in 1999 and 2005, respectively. He was with Siemens, Nokia Siemens Networks, and Coriant, Munich, Germany, working on transmission aspects in optical communications in different research and development and management functions. Since 2013, he has been the Head of the Research and Technology Department, Coriant. He has published more than 30 articles, including peerreviewed journals, contributed and invited conference publications.
David J. Richardson (F'15) received the B.Sc. and Ph.D. degrees in fundamental physics from Sussex University, Brighton, U.K., in 1985 and 1989 respectively.

He joined theOptoelectronics Research Centre (ORC), SouthamptonUniversity, Southampton, U.K., in 1989 and was awarded a Royal Society University Fellowship in 1991 in recognition of his pioneering work on short pulsed fiber lasers. He is currently the Deputy Director of the ORC with responsibility for the ORC's fiber related activities. His current research interests include amongst others: optical fiber communications, microstructured optical fibers and pulsed high-power fibre lasers. He is a prominent figure in the international photonics community and has published more than 900 conference and journal papers and produced more than 20 patents.

Professor Richardson is a Fellow of the Optical Society of America, the Institute of Engineering and Technology, and was made a Fellow of the Royal Academy of Engineering in 2009.

Yutaka Miyamoto (M'93) was born in Tokyo, Japan, on December 8, 1963. He received the B.E. and M.E. degrees in electrical engineering from Waseda University, Tokyo, Japan, in 1986 and 1988, respectively, and the Dr. Eng. Degree from Tokyo University, Japan.

In 1988, he joined the NTT Transmission Systems Laboratories, Yokosuka, Japan, where he involved in research and development on high-speed optical communications systems including the $10-\mathrm{Gb} / \mathrm{s}$ first terrestrial optical transmission system (FA-10G) using EDFA inline repeaters. He then joined NTT Electronics Technology Corporation between 1995 and 1997, where he involved in the planning and product development of high-speed optical module at the data rate of $10 \mathrm{~Gb} / \mathrm{s}$ and beyond. Since 1997, he has been with NTT Network Innovation Labs, where he was involved in the research and development of optical transport technologies based on $40-$ and $100-\mathrm{Gb} / \mathrm{s}$ channel. He is currently the Senior Distinguished Researcher and the Director of Innovative Photonic Network Research Center in NTT Network Innovation Laboratories. His current research interest includes high-capacity optical transport systems with advanced modulation formats, digital signal processing, and space-division multiplexing.

Dr. Miyamoto is a Fellow of the Institute of Electronics, Information and Communication Engineers (IEICE), and is a member of the Institute of Electrical and Electronics Engineers (IEEE).

Toshio Morioka received the B.E. degree in applied physics from Waseda University, Tokyo, Japan in 1982, the M.S. degree in optical sciences from the Optical Sciences Center at the University of Arizona, USA in 1984, and the M.S. and Ph.D. degrees in physics and applied physics from Waseda University in 1985 and 1995, respectively.

In 1985, he joined Yokosuka Electrical Communication Laboratory of NTT Corporation and was a member of the Photonic Transport Network Laboratory of NTT Network Innovation Laboratories, Yokosuka, Japan. He was with the National Institute of Information and Communications Technology (NICT), Japan from 2005 to 2008 working on new generation networks and Extremely Advanced Transmission (EXAT) technologies which he proposed in order to pursue Pbit/s optical transmission and Exa bit/s networks by developing new transmission fibers and novel multiplexing schemes such as SDM and MDM. From 2008, he was project manager at NTT Network Innovation Laboratories, and has been with the High-Speed Optical Communications Group, DTU Fotonik since October, 2011.

Professor Morioka is a fellow of Optical Society of America (OSA) and IEICE, and a member of the Japan Society of Applied Physics, the Laser Society of Japan, and the IEEE Photonics Society/Communications Society. 